NASA Technical Memorandum 107505

IECEC-97237

\title{
High-Flux, High-Temperature Thermal Vacuum Qualification Testing of a Solar Receiver Aperture Shield
}

Thomas W. Kerslake and Lee S. Mason

Lewis Research Center

Cleveland, Ohio

Hal J. Strumpf

AlliedSignal Aerospace Equipment Systems

Torrance, California

Prepared for the

32nd Intersociety Energy Conversion Engineering Conference cosponsored by AIChE, ANS, SAE, AIAA, ASME, and IEEE Honolulu, Hawaii, July 27-August 1, 1997

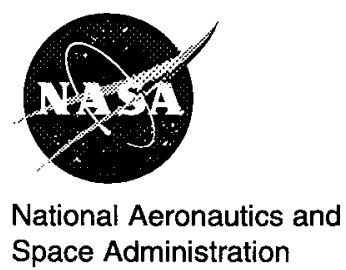

Space Administration 



\title{
HIGH-FLUX, HIGH-TEMPERATURE THERMAL VACUUM QUALIFICATION TESTING OF A SOLAR RECEIVER APERTURE SHIELD
}

\author{
Thomas W. Kerslake \\ NASA Lewis Research Center \\ Cleveland, Ohio 44135 \\ 216-433-5373 (voice) ; 216-433-2995 (fax) \\ Lee S. Mason \\ NASA Lewis Research Center \\ Cleveland, Ohio 44135 \\ 216-977-7106 (voice) ; 216-433-8311 (fax) \\ Hal J. Strumpf \\ AlliedSignal Aerospace Equipment Systems \\ 2525 West $190^{\text {th }}$ St. \\ Torrance, California 90509-2960 \\ 310-512-3359 (voice) ; 310-512-2476 (fax)
}

\begin{abstract}
As part of the International Space Station (ISS) Phase 1 program, NASA Lewis Research Center (LeRC) and the Russian Space Agency (RSA) teamed together to design, build and flight test the world's first orbital Solar Dynamic Power System (SDPS) on the Russian space station Mir. The Solar Dynamic Flight Demonstration (SDFD) program was to operate a nominal $2 \mathrm{kWe}$ SDPS on Mir for a period up to 1-year starting in late 1997. Unfortunately, the SDFD mission was demanifested from the ISS phase 1 shuttle program in early 1996. However, substantial flight hardware and prototypical flight hardware was built including a heat receiver and aperture shield. The aperture shield comprises the front face of the cylindrical cavity heat receiver and is located at the focal plane of the solar concentrator. It is constructed of a stainless steel plate with a $1-\mathrm{m}$ outside diameter, a 0.24-m inside diameter and covered with high-temperature, refractory metal multi-foil insulation (MFI). The aperture shield must minimize heat loss from the receiver cavity, provide a stiff, high strength structure to accommodate shuttle launch loads and protect receiver structures from highly concentrated solar fluxes during concentrator off-pointing events. To satisfy $\mathrm{Mir}$ operational safety protocols, the aperture shield was required to accommodate direct impingement of the intensely concentrated solar image for a 1-hour period.

To verify thermal-structural durability under the anticipated high-flux, high-temperature loading, an aperture shield test article was constructed and underwent a series of two tests in a large thermal vacuum chamber configured with a reflective, pointfocus solar concentrator and a solar simulator. The test article was positioned near the focal plane and exposed to concentrated solar flux for a period of 1-hour. In the first test, a near equilibrium temperature of $1862 \mathrm{~K}$ was attained in the center of the shield hot spot. In the second test, with increased incident flux, a near equilibrium temperature of $2072 \mathrm{~K}$ was achieved.
\end{abstract}

The aperture shield sustained no visible damage as a result of the exposures. This paper describes the aperture shield thermalvacuum qualification test program including the test article, test facility, procedures, data collection, test success criteria, results and conclusions.

\section{INTRODUCTION}

As part of the International Space Station (ISS) Phase 1 program, NASA Lewis Research Center (LeRC) and the Russian Space Agency (RSA) teamed together to design, build and flight test the world's first orbital Solar Dynamic Power System (SDPS) on the Russian space station Mir (lower left portion of Figure 1). The Solar Dynamic Flight Demonstration (SDFD) program was to operate a nominal $2 \mathrm{kWe}$ SDPS on Mir for a period up to 1year starting in late 1997 (Wanhainen and Tyburski, 1995). The SDPS functions by pointing a parabolic reflecting concentrator at the Sun and focusing solar energy into a heat receiver located at the focal point. The receiver transfers heat to a working gas that drives a turboalternator to produce electric power. Waste heat is radiated to space via a heat rejection system.

Unfortunately, the SDFD mission was demanifested from the ISS phase 1 shuttle program in early 1996. However, LeRC is proposing to use the substantial quantity of flight hardware built as part of an all-American SDPS flight demonstration. The demonstration will make use of the SDPD heat receiver (Strumpf, 1995) that has been designed and qualification tested in large part. Of particular importance was thermal-vacuum qualification testing of a critical heat receiver component: the aperture shield.

As shown in Figure 2, the aperture shield (Strumpf et al., 1997) comprises the front face of the cylindrical cavity heat receiver and is located at the focal plane of the solar concentrator. It is constructed of a $0.0095-\mathrm{m}$ thick stainless steel plate with a $1-\mathrm{m}$ outside diameter, a $0.24-\mathrm{m}$ inside diameter and covered with 40 layers of tungsten and molybdenum foil/screen layers (see 
Figure 3). The aperture shield must meet 3 primary requirements: (1) minimize heat loss from the receiver cavity, (2) provide a stiff, high strength structure to accommodate shuttle launch loads and (3) protect receiver structures from highly concentrated solar fluxes during concentrator off-pointing events.

To satisfy Mir operational safety protocols, the aperture shield was required to accommodate direct impingement of the intensely concentrated solar image for a 1-hour period. The focal plane flux distribution, from Kerslake and Fincannon (1995), is shown in Figure 4. Reflective elements of the Russian-built concentrator were to be re-aimed to achieve this distribution with a $82 \mathrm{~W} / \mathrm{cm} 2$ peak flux level. An additional requirement stipulated that reflected solar energy from the aperture shield must be diffuse.

To verify thermal-structural durability under the anticipated high-flux, high-temperature loading, an aperture shield test article was constructed and underwent a series of two tests in a large thermal vacuum chamber configured with a reflective, pointfocus solar concentrator and a solar simulator. This paper describes the aperture shield thermal-vacuum qualification test program including the test article, test facility, procedures, data collection, test success criteria, results and conclusions.

\section{TEST OBJECTIVES AND SUCCESS CRITERIA}

The primary objective of this test was to demonstrate the structural adequacy of the aperture shield outer multi-foil insulation (MFI) layers and structure under severe solar-thermal loading. Severe thermal loading was defined as a one-time exposure to an incident solar flux of $80 \mathrm{~W} / \mathrm{cm} 2$ for a period of 60 minutes in a vacuum environment.

A 60-minute test period was selected since it represented an average orbit insolation time of the Mir space station when the solar dynamic unit would be operating. Theoretically, an onboard emergency could occur at the beginning of the orbit Sun period. This would require the concentrator beam to be offpointed on the aperture shield for this entire 60-minute period. Upon entering the orbit eclipse, the concentrator could then be fully off-pointed in an anti-Sun direction until the emergency was resolved.

The solar beam expected from the off-pointed Russian concentrator during actual operation was nearly Gaussian in shape and had a peak flux of $\sim 80 \mathrm{~W} / \mathrm{cm} 2$. Thus, test conditions were set up to achieve $80 \mathrm{~W} / \mathrm{cm} 2$ peak flux level on the aperture shield test article and faithfully reproduce the vacuum thermal loading anticipating during actual on-orbit operation.

The testing would be considered successful if all of the following criteria were met: (1) the test article was exposed to the required flux levels for at least 30 minutes with 60 minutes as the goal, (2) all required test article data and inspection results were properly recorded, (3) test article sustained no significant surface blistering or warpage and (4) test article sustained no significant screen or foil breakage.

\section{TEST ARTICLE DESCRIPTION}

The test article, shown in Figure 5, was fabricated in nearly the same fashion as the flight aperture shield. The primary exception was that only the 6 outermost tungsten foil/screen layers were laid up in conjunction with layers of zirconia block and quartz blanket insulation and secured to a stainless steel back plate (see Figure 6). This approach was adopted to reduce costs and was justified by the premise that structural damage, if incurred, would be most severe for the outermost foil layers exposed to the highest temperature levels. Four closed-ball, ungrounded, 0.0032-m diameter, tantalum sheathed, type C (W-5\%Re, W$26 \% \mathrm{Re}$ ) thermocouples (TCs) were installed on the test article: three on outermost foil and one below the five tungsten foils (see Figures 5,6 and 7). The type C TC error is $1 \%$ or better in the temperature range $450^{\circ} \mathrm{C}-2320^{\circ} \mathrm{C}$. A circular tungsten foil shield was placed over the TC ball to minimize radiation error. A single type K (chromel-alumel) TC was also mounted on the back plate at a position corresponding to the center of the flux impingement zone.

\section{TEST FACILITY DESCRIPTION}

Aperture shield testing took place at the LeRC Tank 6 Facility. This facility included a $7.6 \mathrm{~m}$ diameter by $21.3 \mathrm{~m}$ length vacuum chamber with liquid nitrogen cold walls, a solar simulator, a Ground Test Demonstrator (GTD) solar dynamic system and a data acquisition system (DACS) (Shaltens and Boyle, 1995). The tank was able to maintain $10^{-6}$ torr vacuum levels during testing. The solar simulator provided approximately one solar constant flux intensity at a $0.5^{\circ}$ collimation angle over the aperture area of a 4.7-m diameter reflective concentrator. The concentrator provided a peak focal plane concentration ratio of 1360 . Test article TCs were read and recorded using a Molytek data logger. An Inframetrics 760 broad-band infrared (IR) camera was used to monitor aperture shield surface temperature distributions. A standard VHS video camera was also used to visually record the appearance of the aperture shield while under test.

\section{TEST PROCEDURES AND TEST MATRIX}

\subsection{Pre-Test Activities}

The test article was attached to the existing GTD receiver located in Tank 6. Using spacers, the test article front face was positioned in a plane parallel to and $0.1 \mathrm{~m}$ in front of the GTD concentrator focal plane (see Figure 7). This position was selected on the basis of concentrator optical analyses to achieve a peak target flux of approximately $80 \mathrm{~W} / \mathrm{cm} 2$. Test article TC instrumentation was connected to the DACS and proper operation was verified. The test article was visually inspected and photographed. Observations and any anomalous features were logged.

The solar simulator light intensity was calibrated and the lamp power level adjusted based on data obtained from several radiometers located on the concentrator. Tank 6 was sealed and the vacuum pumping system was started. Pumping continued for a minimum of 24 hours to allow for material outgassing and vacuum level stabilization.

Just prior to the test start, data acquisition equipment was started and the IR and video cameras were set up to image the test article flux impingement zone. The solar simulator was started and the flow of liquid nitrogen to the cold walls was initiated to achieve a sink temperature of $111 \mathrm{~K}$ or lower for the first test. Cold wall liquid nitrogen flow was not used for the second test since hardware temperatures remained well below maximum limits 
during the first test. This cost-saving decision had no measurable effect on test results since at high absolute temperature levels, the test article radiative heat transfer was not sensitive to ambient sink temperature. As the last pre-test activity, the solar simulator shutter was opened to start the test article exposure.

\subsection{Test Activities}

During the test, aperture shield TC readings were measured and recorded at 2-second intervals. The IR camera output was recorded to VHS tape and approximately 20 IR camera still images were digitally stored. Still images were recorded just before opening the solar simulator shutter and at approximately 1-minute intervals during the test article heat-up and cool-down periods. The video camera output was recorded to VHS tape. Test hardware and facility temperatures were closely monitored by the test operators to give fore warning of any potential temperature limit violations. The solar simulator shutter was closed after a period of 60 minutes to end the test article high flux exposure.

\subsection{Post-Test Activities}

The solar simulator was shut down and all equipment in Tank 6 was allowed to cool-down to ambient temperature. The cold wall liquid nitrogen flow was shut off and the tank was slowly repressurized. The test article was visually inspected and photographed. Observations and any anomalous features (i.e., foil/screen deformation or cracking, discoloration, etc.) were logged.

\subsection{Test Matrix}

Two aperture shield high-flux exposure tests were successfully conducted on December 20, 1995 and March 19, 1996. For the second test, the test article was rotated $180^{\circ}$ prior to be bolted into position to expose a fresh section of the shield. The three surface mounted TCs were repositioned to the shield target zone. Based on post-test analysis of the temperature data, the actual peak aperture shield fluxes achieved during the tests were estimated to be $50 \pm 10 \mathrm{~W} / \mathrm{cm} 2$ and $70 \pm 10 \mathrm{~W} / \mathrm{cm} 2$, respectively, for the December and March tests. In these estimates, the flux uncertainty was introduced by intrinsic TC calibration error and the uncertainty in aperture shield emittance.

\section{TEST RESULTS}

\subsection{Temperature Data}

6.1.1 December 1995 Test. The aperture shield temperature response during this test is shown in Figure 8 . A nearequilibrium temperature of $1862 \mathrm{~K}$ was attained in the center of the shield hot spot while steady temperatures measured by the flanking TCs peaked at $1325 \mathrm{~K}$ and $1200 \mathrm{~K}$. These temperatures were well below the aperture shield temperature limit of $2366 \mathrm{~K}$. The 3 TCs on the aperture shield front surface attained more than $90 \%$ of their final temperature level within the first minute of testing. The fourth TC, buried under 6 foil/screen layers, responded much more slowly and attained a temperature of $1516 \mathrm{~K}$ at the one hour point. A this point, the temperature was still increasing at a rate of $\sim 2 \mathrm{~K} /$ minute. This clearly demonstrated the superior insulating capability of the tungsten multifoil layup. The stainless steel back plate reached a peak temperature of only $349 \mathrm{~K}$ at a point 30 minutes after the solar simulator shutter was closed. This was well below the back plate temperature limit of $811 \mathrm{~K}$ (required to maintain thermal stresses below the stainless steel creep threshold). No hardware or facility temperature limits were exceeded.

Sample IR camera digitized images are shown in Figures 9 and 10. The image in Figure 9 was captured an hour before the test under ambient temperature conditions. The aperture shield inner and outer edges were clearly discernible as were the surfacemounted TCs and $0.05 \mathrm{~m}$ diameter circular TC shields. The image in Figure 10 was captured 11 seconds after the solar simulator shuttle was opened. The shield surface temperature field was established rapidly and corresponded qualitatively very well with the target flux distribution predicted via optical analysis. The image showed the temperature field to be centered around the location of the central TC. This indicated that the test article was properly positioned to receive the concentrated flux field. Data analysis of images taken near the end of the 1-hour test period showed the aperture shield hot spot emittance decreased by 0.05 . This is consistent with published data for grit-blasted tungsten (Touloukian, 1970). The emittance loss is attributed surface morphological changes (asperity relaxation) and grain growth during high temperature exposure.

6.1.2 March 1996 Test. The aperture shield temperature response during this test is shown in Figure 11. The response was very similar to that obtained in the December test except absolute temperature levels were greater due to the higher flux levels. A near-equilibrium temperature of $2072 \mathrm{~K}$ was achieved in the aperture shield hot spot. The flanking TCs measured peak temperatures of $1369 \mathrm{~K}$ and $1139 \mathrm{~K}$ about 3 minutes into the test. After this point, temperatures decreased by $30 \mathrm{~K}$ and $60 \mathrm{~K}$ for the right and left TCs, respectively, by the end of the 1-hour flux exposure period. This observed temperature drop did not affect the fidelity of the aperture shield exposure but was an unexpected result since both the warming of underlying aperture shicld layers and the drop in surface emittance would tend to make temperatures increase with time.

Two possible explanations for this temperature response are: (1) time-temperature dependent MFI thermal conductance and (2) subtle movement of the incident flux field. Explanation (1) is based on the premise that thermal elastic deformation of the foil/screen layup increased the foil to screen contact surface area and/or contact pressure. This would increase the layup thermal conductance and reduce surface temperatures. Explanation (2) is based on the premise that the aluminum build-up assembly platform which supports the concentrator deformed slightly from temperature gradients built up over the 1-hour test period. This deformation would slowly rotate the concentrator resulting in movement of the incident flux field on the aperture shicld target. The flanking TCs would then be exposed to slightly lower flux levels and measure lower temperatures. 


\subsection{Post-Test Condition of the Shield}

The aperture shield sustained no visible damage as a result of these tests. This conclusion was based on visual examination and direct comparison of about 10 photographs of the test article before and after testing. Figure 12 shows a close-up of the aperture shield flux impingement zone following the December test. There were no visible signs of foil or screen warpage, blistering, or cracking. The tungsten wire ties that secured the layup stack were also not damaged as a result of the high flux exposures. By the definition provided in section 2, the aperture shield successfully passed qualification testing to demonstrate the structural integrity of the foil/screen layup.

There was one subtle difference in the visual appearance of the test article after testing: that is, the flux impingement zone had a lighter, slightly more specular appearance than the surrounding surface when viewed along the same line as the light source. This small change in optical properties was attributed to loss in surface micro-roughness due to the high-temperature exposure. A loss in micro-roughness would improve the surface reflectance and specularity over that of the original grit-blasted condition.

Cool temperature surfaces within Tank 6, such as the concentrator, showed no visible film deposits that could result from high temperature vacuum testing of materials. This confirmed that there was no appreciable tungsten sublimation from the aperture shield hot spot. Significant volatilization was not anticipated based on very low tungsten surface recession rates in the aperture shield operating temperature range, i.e. $10^{-13}$ $\mathrm{g} / \mathrm{cm}^{2}$-sec at $2000 \mathrm{~K}$. This is equivalent to less than one monolayer of tungsten lost after the 1-hour exposure.

\section{CONCLUDING REMARKS}

Two high-flux, high-temperature thermal vacuum exposure tests were successfully conducted with a heat receiver aperture shield test article. All test success criteria were met and the aperture shield successfully passed structural integrity qualification testing. The test article did not sustain any visible damage as a result of the tests. With a peak incident flux goal of $80 \mathrm{~W} / \mathrm{cm} 2$, the actual peak flux achieved was estimated to be $70 \pm 10 \mathrm{~W} / \mathrm{cm} 2$. Based on the positive results of this testing, the authors believe that this aperture shield would be tolerant of significantly higher fluxes and temperatures.

\section{REFERENCES}

Kerslake, Thomas W. and Fincannon, James, 1995, "Analysis of Solar Receiver Flux Distributions for US/Russian Solar Dynamic System Demonstration on the Mir Space Station," 30th Intersociety Energy Conversion Engineering Conference Proceedings, Orlando, Florida, p. 399-404.

Shaltens, Richard K., and Boyle, Robert V., 1995, "Initial Results From the Solar Dynamic (SD) Ground Test Demonstration (GTD) Project at NASA Lewis," 30th Intersociety Energy Conversion Engineering Conference Proceedings, Orlando, Florida, p. 363-368.

Strumpf, Hal J., et al., 1995, "Design of a Heat Receiver for the U.S./Russia Solar Dynamic Power Joint Flight Demonstration," 30th Intersocicty Energy Conversion Engineering Conference Proceedings, Orlando, Florida, p. 411-416.
Strumpf, Hal J., et al., 1997, "Design and Analysis of the Aperture Shield Assembly for a Space Solar Receiver," 32nd Intersociety Energy Conversion Engineering Conference Proceedings, paper no. 97347, Honolulu, Hawaii.

Touloukian, Y.S., et al., 1970, Thermophysical Properties of Matter, Vol. 7: "Thermal Radiative Properties - Metallic Elements and Alloys," IFI/Plenum, New York-Washington, p. 796-804.

Wanhainen, Joyce S. and Tyburski, Timothy E., 1995, "Joint US/Russian Solar Dynamic Flight Demonstration Project Plan," 30th Intersociety Energy Conversion Engineering Conference Proceedings, Orlando, Florida, p. 417-420.

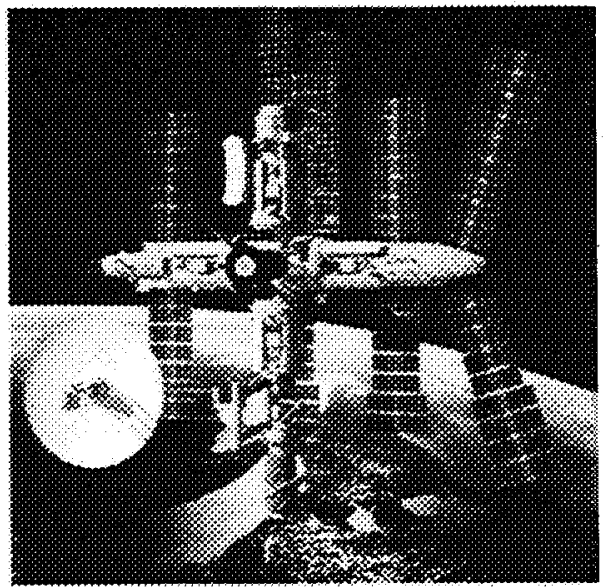

Figure 1, SDFD Hardware on Mir

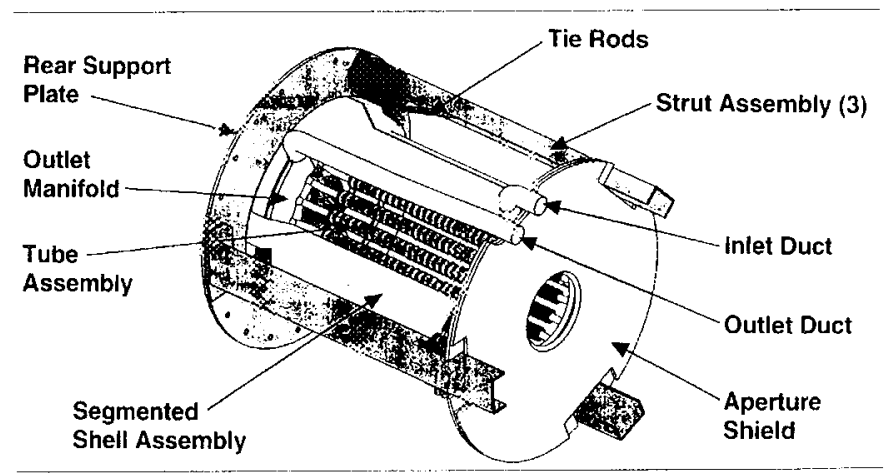

Figure 2. SDFD Receiver 


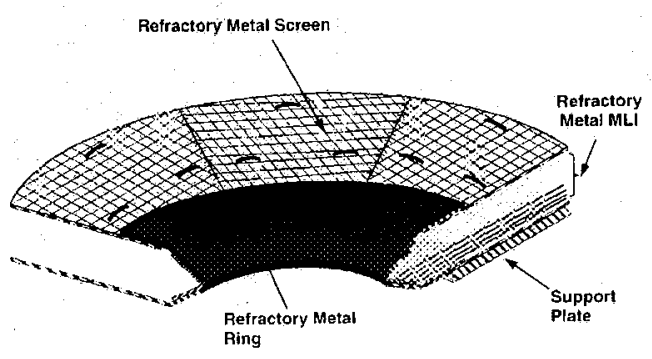

Figure 3. SDFD Aperture Shield

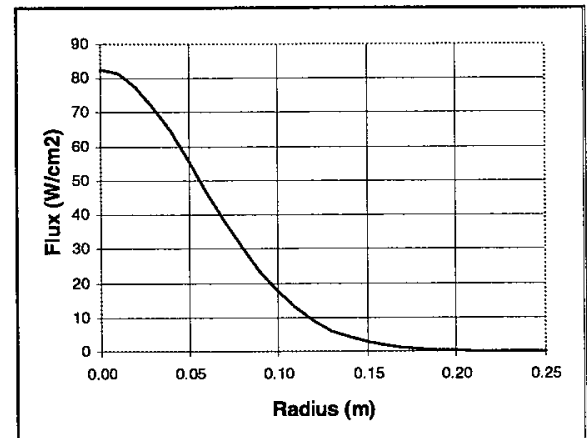

Figure 4. Concentrator Focal Plane Flux Distribution

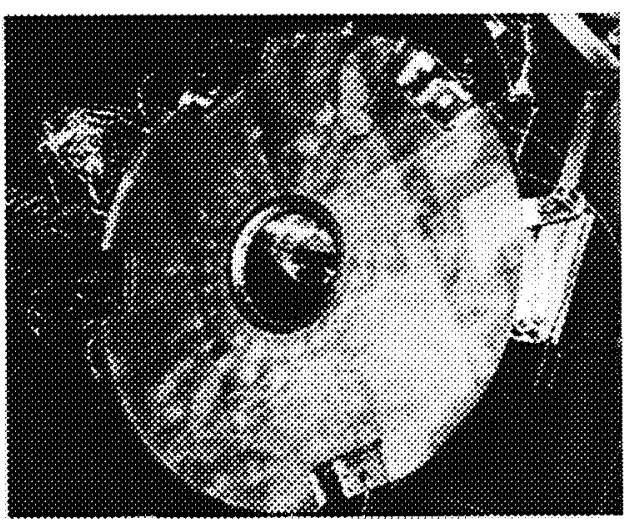

Figure 5. Pre-Test Photograph of Aperture Shield Test Article

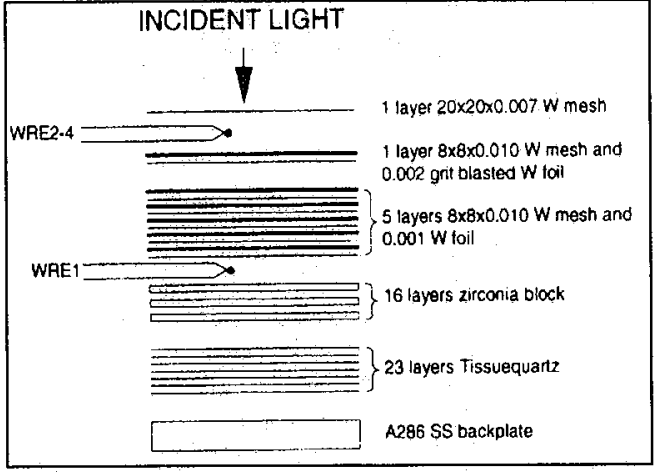

Figure 6. Test Article Cross Section

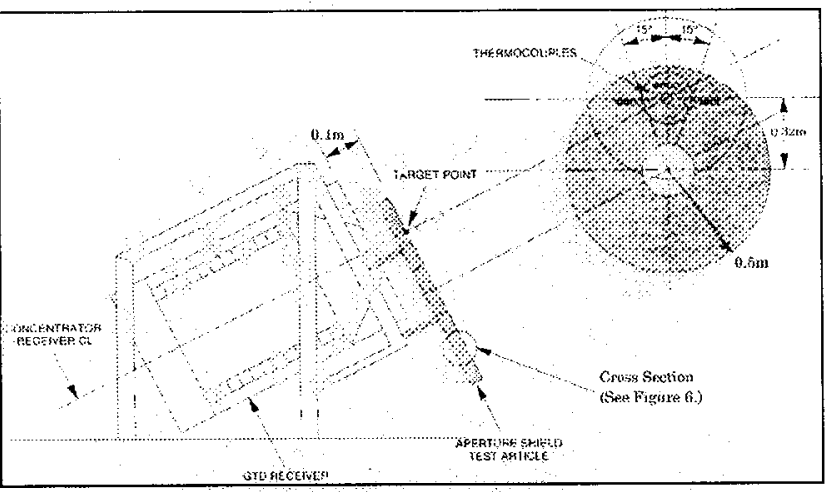

Figure 7. Test Article Layout

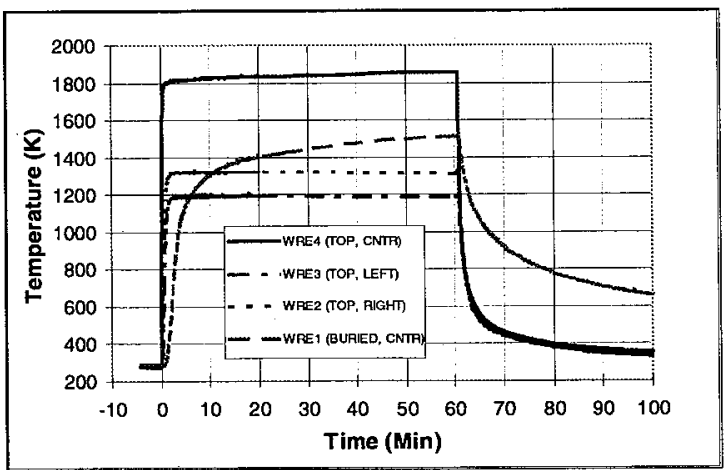

Figure 8. Aperture Shield Temperatures During December 1995 Test 


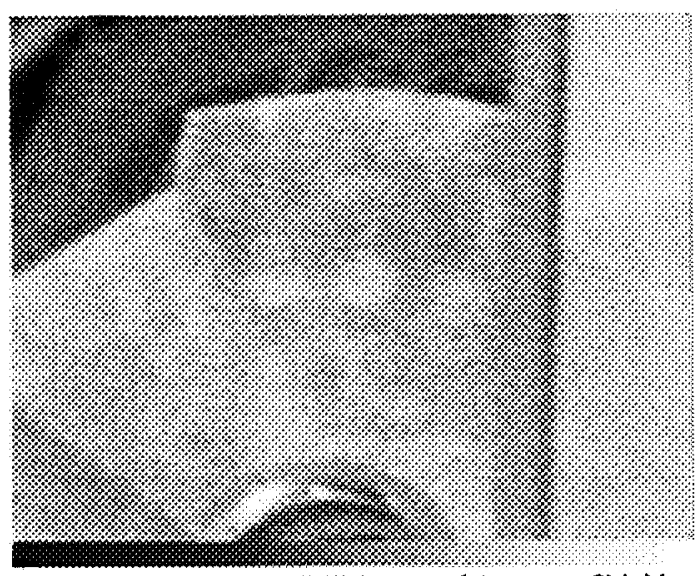

Figure 9. IR Camera Still Image of Aperture Shield At Ambient Temperature

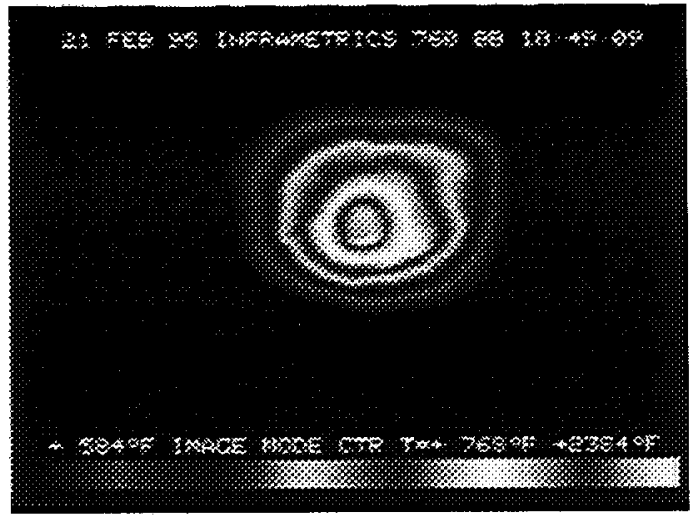

Figure 10. IR Camera Still Image of Aperture Shield 11 Seconds After Solar Simulator Shutter Opening During December 1995 Test

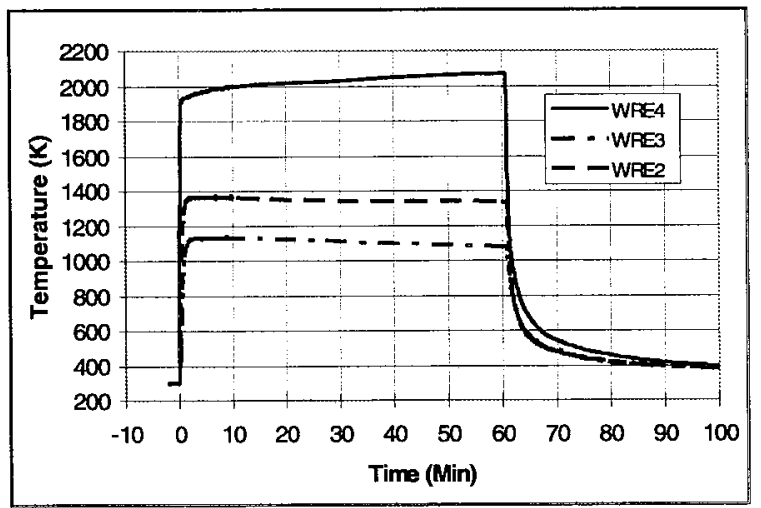

Figure 11. Aperture Shield Temperatures During March 1996 Test

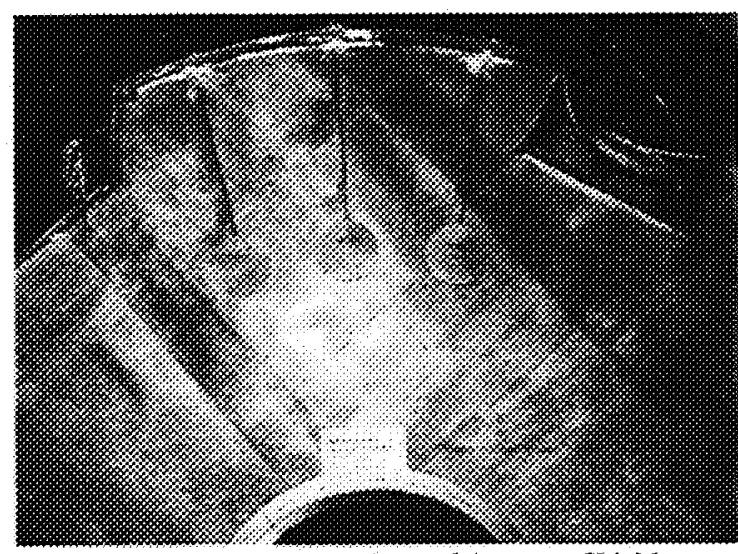

Figure 12. Post-Test Photo of Aperture Shield Flux Impingemnent Zone 


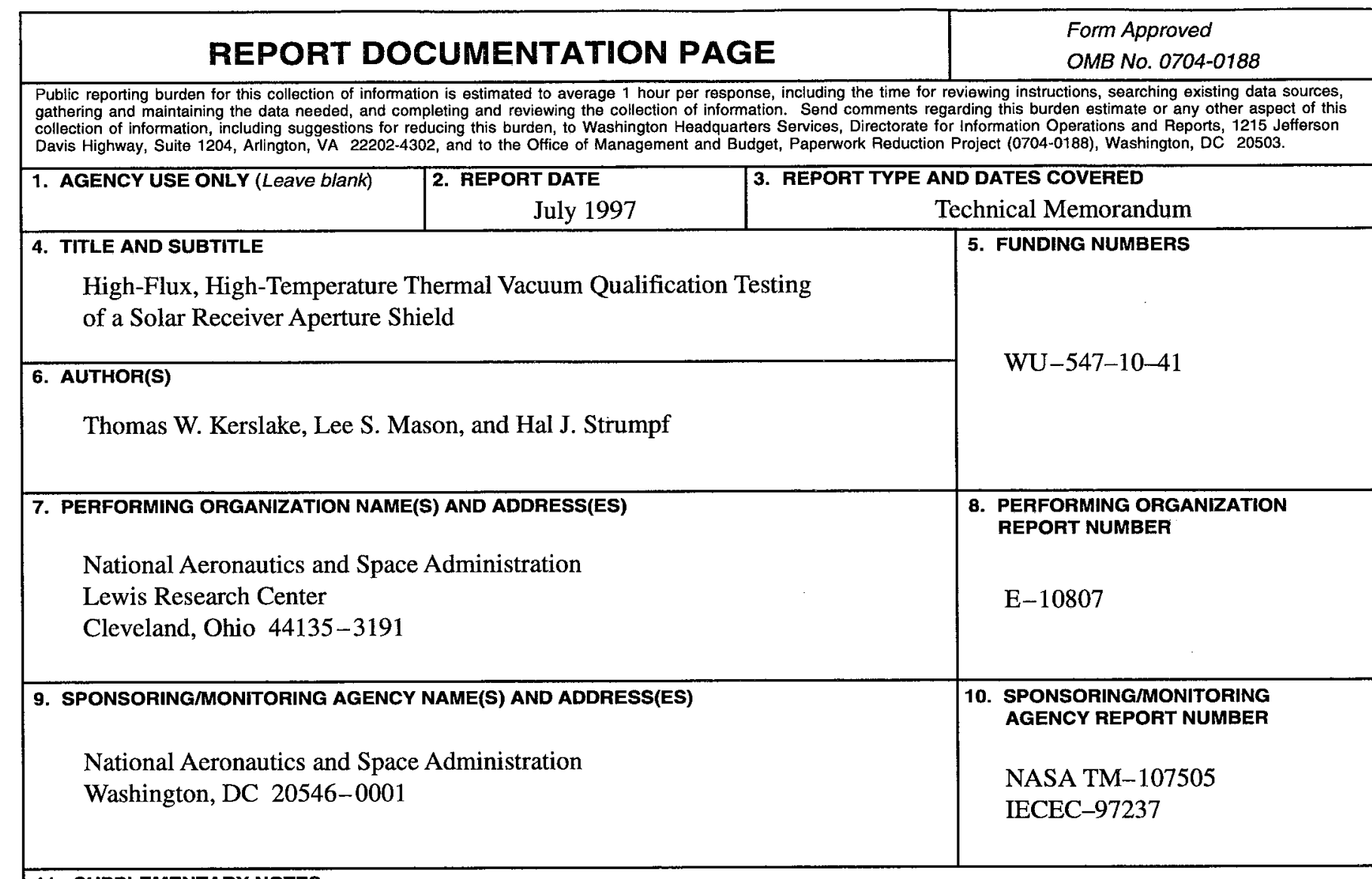

\section{SUPPLEMENTARY NOTES}

Prepared for the 32nd Intersociety Energy Conversion Engineering Conference cosponsored by AIChE, ANS, SAE, AIAA, ASME, and IEEE, Honolulu, Hawaii, July 27-August 1, 1997. Thomas W. Kerslake and Lee S. Mason, NASA Lewis Research Center; Hal J. Strumpf, AlliedSignal Aerospace Equipment Systems, 2525 West 190th Street, Torrance, California 90509-2960. Responsible person, Thomas W. Kerslake, organization code 6920, (216) 433-5373.

12a. DISTRIBUTION/AVAILABILITY STATEMENT $\quad$ 12b. DISTRIBUTION CODE

Unclassified - Unlimited

Subject Categories 18 and 20

This publication is available from the NASA Center for AeroSpace Information, (301) 621-0390.

13. ABSTRACT (Maximum 200 words)

As part of the International Space Station (ISS) Phase 1 program, NASA Lewis Research Center (LeRC) and the Russian Space Agency (RSA) teamed together to design, build and flight test the world's first orbital Solar Dynamic Power System (SDPS) on the Russian space station Mir. The Solar Dynamic Flight Demonstration (SDFD) program was to operate a nominal $2 \mathrm{kWe}$ SDPS on Mir for a period up to 1-year starting in late 1997. Unfortunately, the SDFD mission was demanifested from the ISS phase 1 shuttle program in early 1996. However, substantial flight hardware and prototypical flight hardware was built including a heat receiver and aperture shield. The aperture shield comprises the front face of the cylindrical cavity heat receiver and is located at the focal plane of the solar concentrator. It is constructed of a stainless steel plate with a $1-\mathrm{m}$ outside diameter, a $0.24-\mathrm{m}$ inside diameter and covered with high-temperature, refractory metal multi-foil insulation (MFI). The aperture shield must minimize heat loss from the receiver cavity, provide a stiff, high strength structure to accommodate shuttle launch loads and protect receiver structures from highly concentrated solar fluxes during concentrator off-pointing events. To satisfy Mir operational safety protocols, the aperture shield was required to accommodate direct impingement of the intensely concentrated solar image for a 1-hour period. To verify thermal-structural durability under the anticipated high-flux, high-temperature loading, an aperture shield test article was constructed and underwent a series of two tests in a large thermal vacuum chamber configured with a reflective, point-focus solar concentrator and a solar simulator. The test article was positioned near the focal plane and exposed to concentrated solar flux for a period of 1 -hour. In the first test, a near equilibrium temperature of $1862 \mathrm{~K}$ was attained in the center of the shield hot spot. In the second test, with increased incident flux, a near equilibrium temperature of $2072 \mathrm{~K}$ was achieved. The aperture shield sustained no visible damage as a result of the exposures. This paper describes the aperture shield thermal-vacuum qualification test program including the test article, test facility, procedures, data collection, test success criteria, results and conclusions.

14. SUBJECT TERMS

Solar dynamic power systems; Space stations; Thermal vacuum tests; High temperature tests; Heat shielding; Solar energy; Heat flux; Mir Space Station

\begin{tabular}{|c|c|c|}
\hline $\begin{array}{c}\text { 17. SECURITY CLASSIFICATION } \\
\text { OF REPORT } \\
\text { Unclassified }\end{array}$ & $\begin{array}{c}\text { 18. SECURITY CLASSIFICATION } \\
\text { OF THIS PAGE } \\
\text { Unclassified }\end{array}$ & $\begin{array}{c}\text { 19. SECURITY CLASSIFICATION } \\
\text { OF ABSTRACT } \\
\text { Unclassified }\end{array}$ \\
\hline
\end{tabular}

